\title{
Effects of Benzyladenine and Light on Post-harvest Calamondin (x Citrofortunella microcarpa) Fruit Color and Quality
}

\author{
Yoshitaka Kawai $^{1 *}$, Tadashi Baba ${ }^{1}$, Mika Yoshida ${ }^{1}$, Josephine U. Agravante ${ }^{2}$ \\ and Dormita R. Del Carmen²
}

${ }^{1}$ Department of Agriculture, Tokyo University of Agriculture, Atsugi 243-0034, Japan

${ }^{2}$ Postharvest Horticulture Training and Research Center, College of Agriculture, University of the Philippines Los Baños, Laguna 4031, Philippines

In harvested calamondin fruit, the effects of benzyladenine (BA) and light on the rind color and fruit quality were investigated. BA application delayed degreening of the calamondin fruit in both light and dark conditions. At 5 days, BA application had no influence on total soluble solids (TSS), titratable acid (TA), sugar contents, ascorbic acid (AA), and organic acid in the fruit juice and at 9 days, only AA content has decreased in BA-treated fruits. Light promoted quick degreening of calamondin fruit, whereas in the dark, degreening had proceeded very little in un-treated fruit at 9 days. Light did not influence fruit quality at 5 days either. However, light influenced the sugar content, especially increasing glucose and total sugar, as well as $\mathrm{AA}$ content in fruit at 9 days. Concerning the AA content in calamondin fruit, BA decreased and light increased it. These results indicated that BA treatment after harvest and maintaining fruit in the dark are sufficient to retain the green rind color of harvested calamondin fruit without affecting fruit quality, except for AA content.

Key Words: ascorbic acid content, cytokinin, degreening, light condition, rind color.

\section{Introduction}

Calamondin is an acid citrus which is indigenous to the Philippines and widely cultivated throughout the country. In this citrus fruit, the rind color is an important factor in customer satisfaction. Mature green calamondin fruit of high quality sell for a high price in fresh food markets, and yellowing of the rind results in quality loss, which gives rise to economic loss in the market. During marketing and storage, it is desirable to maintain the green rind color of calamondin.

Plant hormones are related to control of color change in citrus rind and fruit ripening. Although citrus fruit is non-climacteric (Kusunose and Sawamura, 1980), exogenous ethylene promotes a change from green to yellow in rind color and ripens it (Porat, 2008). On the other hand, cytokinin and gibberellin retain the green rind color and inhibit the ripening and senescence of

Received; September 28, 2017. Accepted; December 9, 2017. First Published Online in J-STAGE on February 8, 2018.

This study was supported by the International Cooperative Research Project of the Tokyo University of Agriculture.

* Corresponding author (E-mail: y3kawai@nodai.ac.jp). citrus fruit and both blocked the ethylene-induced change in rind color and ripening of detached citrus fruit (García-Luis et al., 1986). Cytokinins inhibit the destruction of chlorophyll in detached leaves and delay their senescence thorough physiological processes (Thimann, 1980). It has been reported that cytokinin prevents chlorophyll destruction in the rind of green harvested oranges (Eilati et al., 1969), but not in attached satsuma mandarins (García-Luis et al., 1986). Development of a simple method to keep peel green is needed because this is the most important quality in calamondin fruit. Because the effects of cytokinin on rind color of detached calamondin fruit have not been investigated, it was worth testing this approach as a possible means of retaining the green rind.

Light is one of the major environmental factors affecting citrus rind color and is closely involved in the production and decomposition of photosynthesis pigments such as chlorophyll and carotenoids, which give the fruit their color. In satsuma mandarins, Izumi et al. (1992) reported that high-intensity sunlight promoted the coloration of fruit. Yamaga et al. (2016) indicated that exposure to low-intensity red light-emitting diode (LED) irradiation led to development of a degree of 
rind color in post-harvest satsuma mandarin fruit. However, in red grapefruit, light avoidance accelerated chlorophyll breakdown and induced carotenoid accumulation (Lado et al., 2015). On the other hand, it is well known that light induces regreening in citrus fruits (Goldschmidt, 1988).

In this study, we investigated the effect of treatment with a cytokinin (benzyladenine, BA) treatment under light or dark conditions on the rind color and fruit quality of calamondin and thus its effectiveness in delaying the degreening of rind during a short period in shipping and temporary storage.

\section{Materials and Methods}

Mature green calamondin (x Citrofortunella microcarpa (Bunge) Wijnands) fruit were obtained from the Citrus Research Station, NARO Institute of Fruit Tree Science, Japan. The 255 individual fruits used were selected for uniform maturity and size, and were graded as having a green rind. They were divided into groups consisting of 15 fruit. At the start of the experiments, the 15 fruit in each group were assessed for rind color and fruit quality. The rest of the groups were treated with $0,1,10$, or $100 \mathrm{ppm} \mathrm{BA}$ in either light or dark conditions. Fruit were put into low-density polyethylene bags $(230 \times 340 \times 0.03 \mathrm{~mm})$ and sprayed with BA solution. The bags were then closed and stored in a Biotron LH-220N growth chamber (Nippon Medical \& Chemical Instrument Co. Ltd., Osaka, Japan) either under the light condition (temperature $25^{\circ} \mathrm{C}$ constant, fluorescent light, 16h-photoperiod) or in dark conditions, in which the bags of fruit were placed into a lighttight steel box before storage in the same growth chamber. At 5 and 9 days after treatment, the rind color $\left(a^{*}\right)$ of the fruit was measured by a ZE2000 color meter (Nippon Denshoku Industries Co., Ltd., Tokyo, Japan). The fruit juice extracted from the fruit was analyzed for total soluble solids (TSS), titratable acidity (TA), sugars (fructose, glucose, sucrose), ascorbic acid (AA), and organic acids (citric acid, malic acid). TSS was determined with a PAL-1 refractometer (Atago Co., Ltd., Tokyo, Japan). TA was measured by the neutralization titration of juice with $0.1 \mathrm{~N} \mathrm{NaOH}$ and was expressed as grams of citric acid in $100 \mathrm{~mL}$ of juice.

\section{Analysis of sugars, AA, and organic acids}

The extracted fruit juice was passed through a membrane filter $(0.45 \mu \mathrm{m})$ and analyzed for sugars and organic acids. For AA analysis, an aliquot of the fruit juice was mixed with 5\% metaphosphoric acid $(1: 1 \mathrm{v} / \mathrm{v})$ immediately after extraction.

Sugars were analyzed by high-performance liquid chromatography (HPLC) on a Shimadzu liquid system equipped with an LC-6A pump, a RID-6A refractive index detector (Shimadzu Corporation, Kyoto, Japan) and personal computer installed with ChromatoPro software (Run Time Corporation, Hachioji, Japan). A UK-
Amino column $(4.6 \times 250 \mathrm{~mm})$ coupled to a UK-Amino guard column $(2 \times 5 \mathrm{~mm})$ (Imtakt Corporation, Kyoto, Japan) was used and the mobile phase was acetonitrile:water (75:25). Analytical conditions were as follows: flow rate $1 \mathrm{~mL} \cdot \mathrm{min}^{-1}$ : column temperature $40^{\circ} \mathrm{C}$. AA was analyzed by HPLC with a Shimadzu liquid system equipped with an SPD-20A UV-VIS detector (Shimadzu Corporation) and ChromatoPro software. An ODS 2551-P $(6 \times 200 \mathrm{~mm})$ (Senshu Scientific, Tokyo, Japan) was used with isocratic elution by a mobile phase of $1.5 \%$ ammonium dihydrogen phosphate $\left(\mathrm{NH}_{4} \mathrm{H}_{2} \mathrm{PO}_{4}\right)$ (pH 3.8). Analytical conditions were as follows: flow rate $1 \mathrm{~mL} \cdot \mathrm{min}$ : detection wavelength $254 \mathrm{~nm}$ : column temperature $40^{\circ} \mathrm{C}$. Organic acids were analyzed by HPLC with a Shimadzu liquid system equipped with an LC-10A, an SPD-20A UV-VIS detector (Shimadzu Corporation) and ChromatoPro software. A Supelcogel H column $(7.8 \times 300 \mathrm{~mm})$ coupled to a Supelguard C610H guard column (Supelco, Bellefonte, USA) was used with isocratic elution by a mobile phase of $0.1 \%$ phosphoric acid. Analytical conditions were as follows: flow rate $0.5 \mathrm{~mL} \cdot \mathrm{min}^{-1}$ : detection wavelength $210 \mathrm{~nm}$ : column temperature $30^{\circ} \mathrm{C}$.

\section{Statistical analysis}

Data on peel color were analyzed for statistical significance using Statcel3 software (OMS Publishing Inc., Tokorozawa, Japan) by Dunnett's multiple range test. All other statistical analyses were performed using Excel statistics 2010 (Social Survey Research Information, Tokyo, Japan) with a two-way ANOVA and Tukey's test.

\section{Results}

\section{Fruit color}

Under light conditions, the $a^{*}$ value in the rind of calamondin fruit increased with decreasing concentrations of BA at both 5 and 9 days after treatment (Fig. 1). Rind color at $10 \mathrm{ppm}$ and $100 \mathrm{ppm} \mathrm{BA}$ treatment showed no changes at 5 days when stored in the light, but at 9 days after treatment, untreated rind showed the maximum $a^{*}$ value and degreening had mostly proceeded. Under dark conditions, the $a^{*}$ values at 5 days in all BA treatments were similar to the initial 0 -day values, and all fruits kept their green color. On the other hand, at 9 days, only the a* value of untreated fruit had increased, whereas the peel color in the 1,10 , and $100 \mathrm{ppm}$ BA treatments had not changed. Although light promoted peel degreening of the harvested calamondin fruit, BA delayed it.

\section{Fruit quality}

As for fruit quality, TSS and TA in calamondin juice did not differ significantly among BA treatments or between light and dark conditions at 5 and 9 days after treatment (Table 1). However, TSS at 9 days after treatment was influenced by the interaction between BA and 


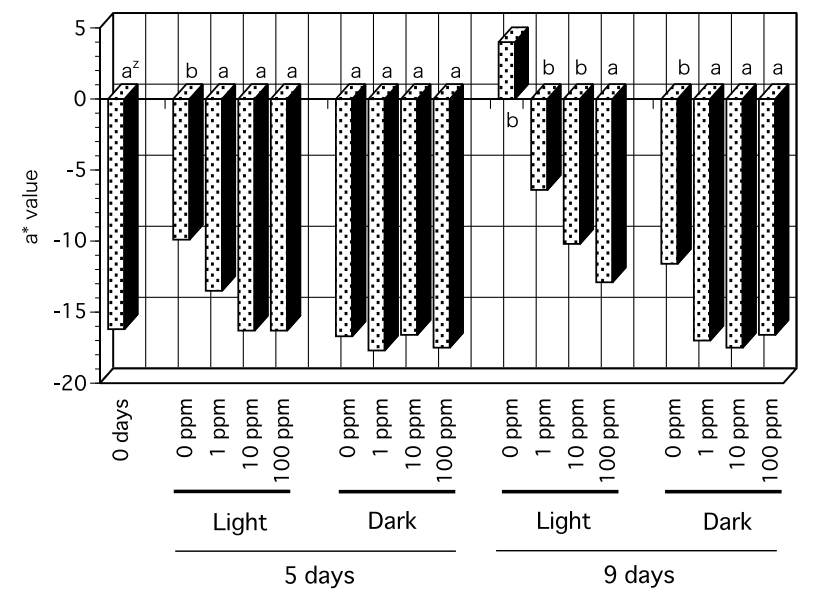

Fig. 1. The effect of $B A$ and light conditions on calmondin fruit color (a* value) at 5 days and 9 days after treatment. The concentrations of $\mathrm{BA}$ at experimental start ( 0 days) were 0 $100 \mathrm{ppm}$. Negative a* values are shown by green and positive values by red. Different letters from the control ( 0 days $)$ indicate significant differences as compared to control fruit in Dunnett's multiple range test $(P<0.05, \mathrm{n}=15)$.

Table 1. The effects of BA treatment and light conditions on TSS and TA in calamondin fruit at 5 days and 9 days after treatment.

\begin{tabular}{|c|c|c|c|c|}
\hline Date & Condition & BA treat. & TSS (\%) & TA $(\%)$ \\
\hline 0 days & & & 8.8 & 7.4 \\
\hline \multirow[t]{11}{*}{5 days } & Light & $0 \mathrm{ppm}$ & 8.8 & 7.3 \\
\hline & & $1 \mathrm{ppm}$ & 8.9 & 7.4 \\
\hline & & $10 \mathrm{ppm}$ & 8.5 & 7.2 \\
\hline & & 100 ppm & 8.7 & 7.2 \\
\hline & Dark & $0 \mathrm{ppm}$ & 8.7 & 7.1 \\
\hline & & $1 \mathrm{ppm}$ & 8.6 & 7.1 \\
\hline & & $10 \mathrm{ppm}$ & 8.7 & 7.1 \\
\hline & & $100 \mathrm{ppm}$ & 9.2 & 7.3 \\
\hline & Significance $^{z}$ & BA & NS & NS \\
\hline & & Light & NS & NS \\
\hline & & BA $\times$ Light & NS & NS \\
\hline \multirow[t]{11}{*}{9 days } & Light & $0 \mathrm{ppm}$ & 8.8 & 6.6 \\
\hline & & $1 \mathrm{ppm}$ & 8.7 & 6.6 \\
\hline & & $10 \mathrm{ppm}$ & 8.5 & 6.7 \\
\hline & & 100 ppm & 8.7 & 7.3 \\
\hline & Dark & $0 \mathrm{ppm}$ & 8.4 & 7.1 \\
\hline & & $1 \mathrm{ppm}$ & 8.9 & 6.9 \\
\hline & & 10 ppm & 8.6 & 7.0 \\
\hline & & 100 ppm & 8.8 & 7.0 \\
\hline & Significance $^{z}$ & BA & NS & NS \\
\hline & & Light & NS & NS \\
\hline & & BA $\times$ Light & $*$ & NS \\
\hline
\end{tabular}

${ }^{\mathrm{z}}$ Significance: NS, non-significant; $*, P<0.05$ in two-way ANOVA $(\mathrm{n}=5)$.

exposure to light. The TA of the fruit decreased gradually from the start of the experiment to 5 and 9 days. Sugar content in 5-day fruit was no different among BA treatments or between light and dark conditions (Table
2). In 9-day fruit in the light, glucose, sucrose, and total sugar content of the treatments other than $100 \mathrm{ppm} \mathrm{BA}$ were significantly higher than in 9-day fruit in the dark. On the other hand, fructose, glucose, and total sugar increased and sucrose decreased in 9-day fruit stored in the light relative to 0 -day fruit.

There was no significant difference in AA contents in 5-day fruit between light and dark conditions or BA treatments (Table 3). AA content in fruit stored for 9 days under light conditions was higher than in dark conditions and was decreased significantly by BA treatment. BA and light had no effect on citric acid or malic acid contents in fruit juice at either 5 or 9 days after treatment (Table 3).

\section{Discussion}

The cytokinin BA, which is known to delay degreening and senescence of leaves (Eilati et al., 1969), inhibited chlorophyll decomposition in the rind of calamondin. The inhibitory effects of BA increased at higher concentrations and had a maximum effect at $100 \mathrm{ppm}$. Barmore (1975) reported that chlorophyllase activity and chlorophyll decomposition in calamondin rind are increased by ethylene treatment and a concomitant decrease in chlorophyll occurs. It was also shown that ethylene-induced degreening of citrus fruit is inhibited by BA. Although citrus is a non-climacteric rise type of fruit, the endogenous ethylene level at the ripening stage reportedly reaches a maximum in seedless yuzu and wase satsuma mandarins when the color changes from green to yellow (Kusunose and Sawamura, 1980). Isshiki et al. (2005) reported that postharvest treatment with 1-methylcyclopropene, an inhibitor of ethylene production, delayed the degreening of peel in sudachi fruit. The delay of degreening in BA-treated fruit may have occurred by repressing the ethylene effect on chlorophyllase activity and chlorophyll decomposition.

In the light, harvested calamondin fruit degreening proceeded quickly as shown by the a* values (Fig. 1). Light is important to the development of the photosynthetic apparatus and is involved in both degreening and regreening in the peel of citrus fruit. Yamaga et al. (2016) reported that low-red LEDs increased the $a^{*}$ value of peel in early-harvest satsuma mandarin fruit. In red grapefruit, high intensity light inhibited chlorophyll breakdown and carotenoid accumulation in the peel of fruit located on the branch (Lado et al., 2015). We infer that light accelerates chlorophyll decomposition and the transformation of chloroplasts into chromoplasts in the rind of detached citrus fruit.

In terms of fruit quality, BA did not influence TSS, TA, and sugar, or organic acid content of calamondin juice with the exception of AA. Cooper and Rasmussen (1968) concluded that degreening of calamondin fruit receiving AA treatment was caused by their release of ethylene. BA treatment may decrease AA in calamon- 
Table 2. The effects of BA treatment and light conditions on sugar content in calamondin fruit at 5 days and 9 days after treatment.

\begin{tabular}{|c|c|c|c|c|c|c|}
\hline Date & Condition & BA treat. & Fructose $(\%)$ & Glucose $(\%)$ & Sucrose $(\%)$ & Total sugar $(\%)$ \\
\hline 0 days & & & 0.35 & 0.34 & 0.53 & 1.22 \\
\hline \multirow[t]{11}{*}{5 days } & Light & $0 \mathrm{ppm}$ & 0.47 & 0.44 & 0.48 & 1.39 \\
\hline & & $1 \mathrm{ppm}$ & 0.41 & 0.43 & 0.38 & 1.22 \\
\hline & & $10 \mathrm{ppm}$ & 0.47 & 0.52 & 0.36 & 1.34 \\
\hline & & $100 \mathrm{ppm}$ & 0.48 & 0.37 & 0.38 & 1.24 \\
\hline & Dark & $0 \mathrm{ppm}$ & 0.39 & 0.35 & 0.44 & 1.19 \\
\hline & & $1 \mathrm{ppm}$ & 0.38 & 0.34 & 0.39 & 1.11 \\
\hline & & $10 \mathrm{ppm}$ & 0.44 & 0.40 & 0.44 & 1.28 \\
\hline & & $100 \mathrm{ppm}$ & 0.45 & 0.41 & 0.41 & 1.27 \\
\hline & Significance $\mathrm{e}^{\mathrm{z}}$ & $\mathrm{BA}$ & NS & NS & NS & NS \\
\hline & & Light & NS & NS & NS & NS \\
\hline & & BA $\times$ Light & NS & NS & NS & NS \\
\hline \multirow[t]{11}{*}{9 days } & Light & $0 \mathrm{ppm}$ & 0.98 & 0.47 & $0.25 \mathrm{ab}^{\mathrm{y}}$ & 1.69 \\
\hline & & $1 \mathrm{ppm}$ & 1.01 & 0.52 & $0.27 \mathrm{a}$ & 1.84 \\
\hline & & $10 \mathrm{ppm}$ & 0.86 & 0.41 & $0.21 \mathrm{ab}$ & 1.48 \\
\hline & & $100 \mathrm{ppm}$ & 0.87 & 0.39 & $0.19 \mathrm{~b}$ & 1.45 \\
\hline & Dark & $0 \mathrm{ppm}$ & 0.74 & 0.33 & $0.18 \mathrm{~b}$ & 1.26 \\
\hline & & $1 \mathrm{ppm}$ & 0.82 & 0.37 & $0.20 \mathrm{~b}$ & 1.38 \\
\hline & & $10 \mathrm{ppm}$ & 0.81 & 0.36 & $0.20 \mathrm{~b}$ & 1.36 \\
\hline & & 100 ppm & 0.95 & 0.43 & $0.21 \mathrm{ab}$ & 1.60 \\
\hline & Significance $^{z}$ & $\mathrm{BA}$ & NS & NS & NS & NS \\
\hline & & Light & NS & $*$ & $* *$ & $*$ \\
\hline & & $\mathrm{BA} \times$ Light & NS & NS & $*$ & NS \\
\hline
\end{tabular}

z Significance: NS, non-significant; *, $P<0.05 ; * *, P<0.01$ in two-way ANOVA (n=5).

${ }^{y}$ Different letters show significant differences by Tukey's test at the $5 \%$ level.

Table 3. The effects of BA treatment and light condition on AA, citric acid, and malic acid in calamondin fruit at 5 days and 9 days after treatment.

\begin{tabular}{|c|c|c|c|c|c|}
\hline Date & Condition & BA treat. & $\mathrm{AA}(\mathrm{mg} / 100 \mathrm{~mL})$ & Citric acid $(\%)$ & Malic acid (\%) \\
\hline 0 days & & & 48.52 & 6.49 & 0.54 \\
\hline \multirow[t]{11}{*}{5 days } & Light & $0 \mathrm{ppm}$ & 44.23 & 6.17 & 0.36 \\
\hline & & $1 \mathrm{ppm}$ & 45.66 & 6.28 & 0.40 \\
\hline & & $10 \mathrm{ppm}$ & 42.62 & 6.22 & 0.41 \\
\hline & & $100 \mathrm{ppm}$ & 43.11 & 6.33 & 0.40 \\
\hline & Dark & $0 \mathrm{ppm}$ & 44.36 & 6.20 & 0.39 \\
\hline & & $1 \mathrm{ppm}$ & 44.31 & 6.02 & 0.38 \\
\hline & & $10 \mathrm{ppm}$ & 40.77 & 6.11 & 0.38 \\
\hline & & $100 \mathrm{ppm}$ & 41.02 & 6.15 & 0.38 \\
\hline & Significance ${ }^{z}$ & BA & NS & NS & NS \\
\hline & & Light & NS & NS & NS \\
\hline & & $\mathrm{BA} \times$ Light & NS & NS & NS \\
\hline \multirow[t]{11}{*}{9 days } & Light & $0 \mathrm{ppm}$ & $51.46 \mathrm{a}^{\mathrm{y}}$ & 6.58 & 0.37 \\
\hline & & $1 \mathrm{ppm}$ & $46.48 \mathrm{abc}$ & 6.14 & 0.33 \\
\hline & & $10 \mathrm{ppm}$ & $49.05 \mathrm{abc}$ & 6.13 & 0.33 \\
\hline & & $100 \mathrm{ppm}$ & $45.85 \mathrm{bc}$ & 6.42 & 0.33 \\
\hline & Dark & $0 \mathrm{ppm}$ & $47.06 \mathrm{abc}$ & 5.81 & 0.37 \\
\hline & & $1 \mathrm{ppm}$ & $46.80 \mathrm{abc}$ & 6.35 & 0.41 \\
\hline & & $10 \mathrm{ppm}$ & $42.27 \mathrm{c}$ & 6.25 & 0.37 \\
\hline & & $100 \mathrm{ppm}$ & $44.42 \mathrm{bc}$ & 6.09 & 0.31 \\
\hline & Significance $^{\mathrm{z}}$ & BA & $* *$ & NS & NS \\
\hline & & Light & $* *$ & NS & NS \\
\hline & & $\mathrm{BA} \times$ Light & $*$ & NS & NS \\
\hline
\end{tabular}

z Significance: NS, non-significance; *, $P<0.05$; **, $P<0.01$ in two-way ANOVA (n=5).

y Different letters show significant differences by Tukey's test at the $5 \%$ level. 
din juice directly. Although there were no significant differences in TSS, TA, or organic acid content of fruit juice between light and dark conditions, the content of sugars and AA was higher in the light than the dark. Huff (1984) reported that calamondin fruit accumulated soluble sugars in the pericarp as degreening was initiated. We suggest that light accelerates both the degreening and the accumulation of sugars. The accumulation of sugar is an important factor in the quality of some citrus fruits, but it is less important for the quality of calamondin fruit because the fruit has a low sugar content. Consequently, storage in the dark is better at preserving the green rind color after harvest.

This study showed that BA-treated fruit stored under dark conditions retained a green rind color similar to that of newly harvested fruit for at least 9 days, which should allow short-term shipment and storage.

\section{Acknowledgements}

We are grateful to the NARO Institute of Fruit Tree Science, Japan for fruit material.

\section{Literature Cited}

Barmore, C. R. 1975. Effect of ethylene on chlorophyllase activity and chlorophyll content in calamondin rind Tissue. HortScience 10: 595-596.

Cooper, W. C. and G. K. Rasmussen. 1968. Induction of degreening of tangerines by preharvest applications of ascorbic acid, other ethylene-releasing agents. Citrus Industry 49: 25-27.

Eilati, S. K., E. E. Goldshmidt and S. P. Monselise. 1969. Hormonal control of clour changes in orange peel. Experientia 25: 209-210.
García-Luis, A., F. Fornes and J. L. Guardiola. 1986. Effects of gibberellin A3 and cytokinins on natural and post-harvest ethylene-induced pigmentation of Satsuma mandarin peel. Physiol. Plant. 68: 271-274.

Goldschmidt, E. E. 1988. Regulatory aspects of chlorochromoplast interconversions in senescing Citrus fruit peel. Israel J. Bot. 37: 121-130.

Huff, A. 1984. Sugar regulation of plastid interconversions in epicarp of citrus fruit. Plant Physiol. 76: 307-312.

Isshiki, M., H. Terai and Y. Suzuki. 2005. Effect of 1methylcyclopropene on quality of sudachis (Citrus sudachi hort. Ex Shirai) during storage. Food Preservation Sci. 31: $61-65$.

Izumi, H., T. Ito and Y. Yoshida. 1992. Effect of light intensity during the growing period on ascorbic acid content and its histochemical distribution in the leaves and peel, and fruit quality of satsuma mandarin. J. Japan. Soc. Hort. Sci. 61: 715.

Kusunose, H. and M. Sawamura. 1980. Ethylene production and respiration of postharvest acid citrus fruits and wase satsuma mandarin fruit. Agric. Biol. Chem. 44: 1917-1922.

Lado, J., P. Cronje, B. Alquézar, A. Page, M. Manzi, A. GómezCadenas, A. D. Stead, L. Zacarías and M. J. Rodrigo. 2015. Fruit shading enhances peel color, carotenes accumulation and chromoplast differentiation in red grapefruit. Physiol. Plant. 154: 469-484.

Porat, R. 2008. Degreening of citrus fruit. Tree Forestry Sci. Biotechnol. 2: 71-76.

Thimann, K. V. 1980. The senescence of leaves. p. 85-115. In: K. V. Thimann (ed.). Senescence in Plants. CRC Press, Boca Raton, Florida.

Yamaga, I., Y. Shirai, T. Nakajima and Y. Kobayashi. 2016. Rind color development in satsuma mandarin fruits treated by low-intensity red light-emitting diode (LED) irradiation. Food Sci. Technol. Res. 22: 59-64. 